\title{
The Length Of Bearing Pressure Zone For The Flat Seams Extraction In A Linear Deformation Rock
}

\author{
Vjacheslav Gogolin ${ }^{1, *}$, Yury Lesin ${ }^{1}$, Anna Djagileva ${ }^{1}$ \\ ${ }^{1}$ T.F. Gorbachev Kuzbass State Technical University, 650000, 28 Vesennyaya St., Kemerovo, Russia
}

\begin{abstract}
The article describes the problem of numerical calculation of stress-strain state of the rock mass during flat seams extraction by finite element method. The distribution of bearing pressure under changing the seam thickness and depth of development is described. The length of the bearing pressure zones for different references of the pressure was defined. The independence of the bearing pressure zone length on the depth of development was proved. The analytical dependence of the bearing pressure zone length on the seam thickness was obtained. This result defines the influence of mining area on geo-mechanical condition of mine workings.
\end{abstract}

\section{Introduction}

The calculation of the bearing pressure zone length is one of the main tasks of geomechanics at coal seams mining. A lot of works are devoted to the solution of this problem, in which we underline a few different approaches to the formulation of solutions and methods [1-4]. In this paper, the method of finite element numerical simulation of the stressstrain state of the rocks was used to define the linear deformation of the rock [5-7]. This approach is implemented in solving various problems of geo-mechanics in coal seams underground mining $[8,9]$. In this paper, the area of influence of mining works, depending on the depth, design and capacity of the coal seam was defined.

\section{Materials and methods}

The object of research is the length of the coal seam of high stress zone. To address the issue of the length of the bearing pressure zones it is necessary to analyze the stress state of the coal seam. For the calculation of the stress-strain state of the rocks near mining working the finite element method was used, and the series of numerical experiments were conducted.

\footnotetext{
${ }^{*}$ Corresponding author: gva.pm@kuzstu.ru
} 


\section{Results and discussion}

The diagram of the problem of calculating the stress-strain state of the rocks in the development of mining works is shown in Fig. 1. Estimated rectangular area included the following units: 1 - the coal seam; 2 - the rock caving in goaf; 3 - the seam's roof and the soil containing rocks. The boundary conditions and loads are taken in the following form. At the upper boundary of the estimation area $A B$ there is no load (full surface). At the lower boundary of the $\mathrm{CD}$, remote from the pillar, there is no normal displacement (the border is secured). Vertical boundaries $\mathrm{BC}$ and $\mathrm{AD}$, rather remote from the mining face do not feel the effect of the mining working and have no horizontal displacement.

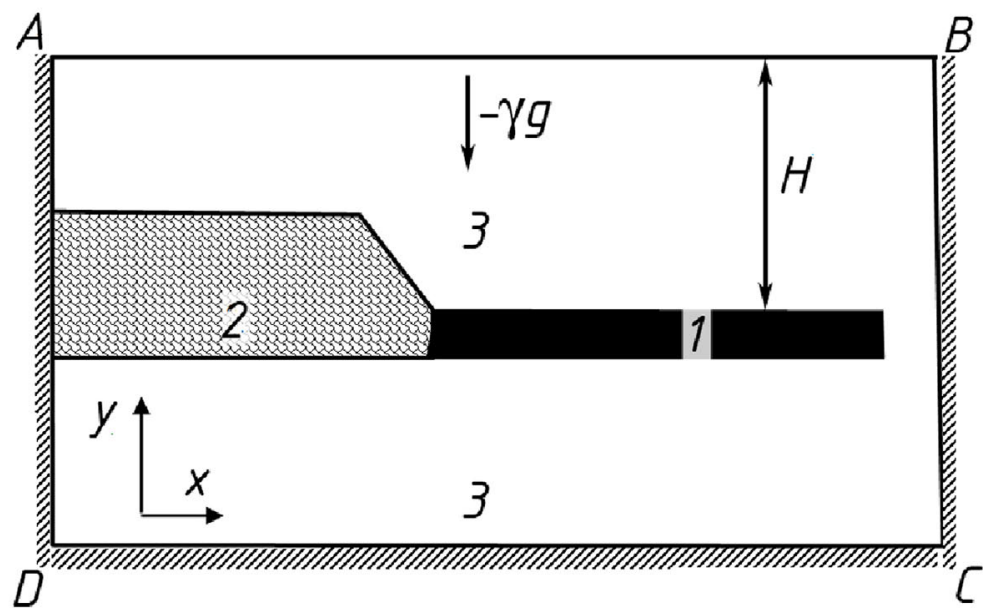

Fig. 1. The design scheme: 1 - coal seam; 2 - the goaf; 3 - host rocks

The rock of roof and soil are loaded by the volume strength $\gamma=25000 \mathrm{~N} / \mathrm{m}^{3}$ corresponding weight of host rocks; Young's module $E=1010 \mathrm{~N} / \mathrm{m}^{2}$, Poisson ratio $v=0,25$.

Coal seam is loaded by volumetric force $\gamma=14000 \mathrm{~N} / \mathrm{m}^{3}, E=109 \mathrm{~N} / \mathrm{m}^{2}, v=0.25$.

Caving in goaf has a capacity of five times more than the thickness of the seam with the following characteristics: $\gamma=20000 \mathrm{~N} / \mathrm{m}^{3}, E=10^{9} \mathrm{~N} / \mathrm{m}^{2}, v=0.25$.

Seam thickness ranged from 1 to $10 \mathrm{~m}$, the depth of development - from 200 to $1000 \mathrm{~m}$. The stress-strain state of the area of estimation is described by linear deformable blocks behavior. The problem was solved by finite element method (FEM) using licensed program «ELCUT». Fig. 2 shows the example of vertical stress distribution in excess of their initial value, i.e., high rock pressure zone (lightly background) and unloading zone (dark background). In this example the seam thickness was $2 \mathrm{~m}$, the depth of development $-400 \mathrm{~m}$.

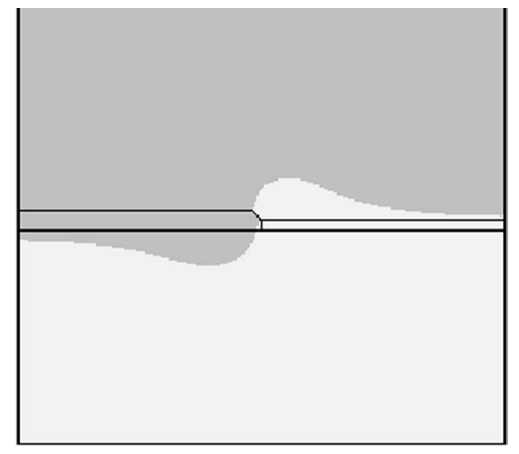

Fig. 2. The distribution of high and low vertical stresses near the working 
The distribution of high and low stresses corresponds to dominating opinions about unloading zones position in rock arrays of the seam's roof and soil during coal mining [10$12]$. The bearing pressure distribution in the seam for the same conditions in the linear deformed rocks is shown in Figure 3. Here the compressive stresses are taken negative.

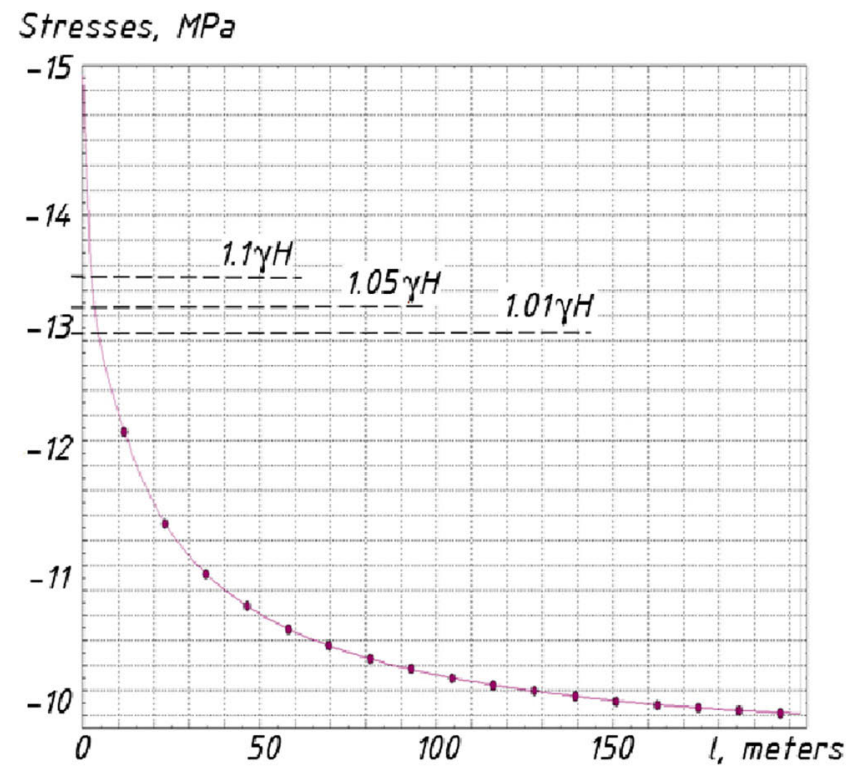

Fig. 3. Bearing pressure distribution in linear deformed rocks

The most remote point of the seam from mining stope (at which the increment of the bearing pressure relative to $\gamma H$ is $5 \%$ ), is considered to be the boundary of the bearing pressure. Also, the bearing pressure value increments of $10 \%$ can be used as the boundary threshold value. This paper observes three possible values of the length of bearing pressure zone accordingly the increments of the bearing pressure of $10 \%, 5 \%$ and $1 \%$, and designated as $l_{10}, l_{5}, l_{1}$. The length of the bearing pressure zones was determined with accuracy up to $1 \mathrm{~m}$. The values of these lengths with seam thickness of $2 \mathrm{~m}$ for different depth of mining works are shown in Table 1.

Table 1. The length of bearing pressure zone

\begin{tabular}{|c|c|c|c|c|c|}
\hline \multirow{2}{*}{ The length } & \multicolumn{5}{|c|}{ The depth of mining works, m } \\
\cline { 2 - 6 } & 200 & 400 & 600 & 800 & 1000 \\
\hline$l_{10}, \mathrm{~m}$ & 39 & 41 & 42 & 43 & 43 \\
\hline$l_{5}, \mathrm{~m}$ & 69 & 74 & 76 & 77 & 78 \\
\hline$l_{1}, \mathrm{~m}$ & 150 & 153 & 157 & 158 & 161 \\
\hline
\end{tabular}

Accordingly the results of calculations of the length of the bearing pressure zones (Table 1) we concluded that during changing the depth of working of 200 to $1000 \mathrm{~m}$ the lengths vary by less than $10 \%$ relatively their average value. Therefore, we can assume that for linear deformed rocks the depth of mining works does not affect the length of the bearing pressure zone. And you can only specify one, the average length of each seam thickness. Thus, for seam thickness of $2 \mathrm{~m}$ the average bearing pressure zone lengths are 42, 75 and 155 meters for $10 \%, 5 \%$ and $1 \%$ increment of the bearing pressure pressures $\gamma H$. This result can be explained by the fact that with increasing the depth of mining works the percentage increment of bearing pressure increases in proportion. A similar result (the inde- 
pendence of the bearing pressure zone length on the depth of mining works) was obtained for each seam thickness from 1 to $10 \mathrm{~m}$.

According to the results of numerical experiments the regression and correlation analysis were conducted, and the dependences of bearing pressure zone length on the seam thickness $m$ were obtained. From considering extend, quadratic and logarithmic dependencies the logarithmic was recognized as the most significant with the following equations:

$$
\begin{array}{cc}
l_{10}=34.3 \cdot \ln (m)+18.3 ; & \left(R^{2}=0.997\right) \\
l_{5}=44.1 \cdot \ln (m)+41.8 ; & \left(R^{2}=0.987\right) \\
l_{1}=34.1 \cdot \ln (m)+119.0 ; & \left(R^{2}=0.917\right)
\end{array}
$$

The existing graphical dependence of bearing pressure zone length on the depth of mining works was obtained for rocks with the other deformation properties.

\section{Conclusions}

1. In the linear deformed rocks the length of the bearing pressure zone length does not depend on the depth of mining works.

2. The length of the bearing pressure zone depends logarithmically on the flat seam thickness in the limits from 1 to $10 \mathrm{~m}$.

3. These dependencies form the area of geo-mechanical influence of mining works.

The authors thank JSC "SUEK-Kuzbass" for financial support of this research.

\section{References}

1. B.H.G. Brady, E.T. Brown, Rock Mechanics for underground mining (Springer science, 2005)

2. J. Jaeger, N.G. Cook, R. Zimmerman, Fundamentals of rock mechanics (Wiley Blackwell, 2007)

3. M. Pastor, C. Tamaonini, Numerical modeling in geomechanics (Kogan Page science, 2004)

4. J.A. Hudson, J.P. Harrison, Engineering rock mechanics. An introduction to the principles (Pergamon press, 2000)

5. O.C. Zienkiewicz, R.L. Taylor, J.Z. Zhu, The Finite Element Method: Its Basis and Fundamentals (7th Edition) (Butterworth-Heinemann, 2013)

6. O. Fusao, Computer methods and recent advances in geomechanics (CRC Press, 2014)

7. M. Fremond, F. Maceri, Mechanical modeling and computational issues in civil engineering (Springer, 2005)

8. V.A. Gogolin, Y.A. Ryzhkov, Soviet Mining Science, 13, 17 (1977)

9. V.M. Seryakov, J. Min. Sci., 45, 420 (2009)

10. M.V. Kurlenya, V.E. Mirenkov, V.A. Shutov, J. Min. Sci. 50, 1001 (2014)

11. V.A. Gogolin, Y.A. Ryzhkov, Soviet Mining Science 17, 156 (1981)

12. Y.A. Ryzhkov, Y.V. Lesin, V.A. Gogolin, N.V. Karpenko, J. Min. Sci. 32, 188 (1996) 